\title{
A STUDY ON IMPACT OF BEHAVIOURAL FINANCE ON INVESTMENT DECISION OF SINGLE PARENTS IN SOUTH ASIAN COUNTRIES
}

\author{
Kannadas Sendilvelu \\ Assistant Professor of Accounting and Finance \\ SDM Institute for Management Development \\ Mysuru, India-570011 \\ E-mail: Kannadas100@gmail.com \\ Dr. Manita Deepak Shah \\ Professor and Associate Dean \\ Jain (Deemed to be) University \\ Bengaluru, India-560069 \\ E-mail: manita2736@gmail.com
}

\begin{abstract}
The purpose of this study is to find out the possible impact of behavioural finance on the investment decision of a single parent. As being an earning/working single parent who usually does not have other possible sources in their family, the decision which they take must be a reliable one and cannot afford to get a second chance. In the study, this study is also one of an effort to assess the impact of behavioural biases in the investment decision-making of a single parent. A questionnaire is designed and responses are collected from 203 respondents who prefer to invest where the level of risk is either low or moderate and are more concerned about losses in their investment than substantial gain. Also, most of the respondents were investing in order to meet some specific purpose, for their retirement plan as well as to educate their children. This study concludes by stating that investors' risk-taking capacity is dependent on their level of income and the sources of income. Although every Individual is subject to some biases, they tend to think more rational way than an average investor in many ways as they know about their requirements and the investment they make.
\end{abstract}

Keywords: Behavioural Finance, Investment Decision, Single Parent.

JEL Classification Codes: G40, G41.

\section{INTRODUCTION}

Individual investor's behaviour is extensively influenced by various biases that are highlighted in the growing discipline of behavioural finance. Therefore, this research is part of an attempt to determine the effect of behavioural biases on a single parent's investment decision-making. Behavioural finance is a comparatively recent area that attempts to combine behavioural and psychological theory with traditional economic and financial theory in order to provide reasons for why people make irrational financial decisions. It is a well-known term in the stock market for investment options all over the world. Behavioural finance is the study of the impact of psychology and sociology on monetary practitioner's behaviour. It is essential to examine why people buy or sell stocks without doing basic research or acting irrationally when making investment decisions. 
The investment behaviour of a single parent is a very important topic in the present scenario. Even as a single parent they face many challenges, having their finances in order can help ease the situation. Having a grip on their finances can make the journey a little smoother later because the current investment is done. Savings of the single parents are invested in assets depending on their risk and return demands, safety, liquidity, the available avenues for investment, various financial institutions, etc. It is important to study how they manage to save their money and invest in the longterm future so that they define and prioritize their financial goals. Hence, a study of investing behaviour of single parents in India has made with the objective of understanding the level of knowledge of households about investment.

\section{REVIEW OF LITERATURE}

The aim of the paper is to analyse behavioural finance theory objectively and to define property issues for behavioural analysis. The evidence that the market is incompetent or at best only weak-form efficient, suggests that assets investors do not always hold on to rationality and are influenced by emotions. Hence, Behavioural finance theories are thought to have a lot to say when it comes to evaluating property investments. Psychological biases affect investor behaviour and asset prices, according to behavioural finance Investors use historical results to measure current stock market performance. They do not have all asset forms. When deciding, investors' perspectives will alter as they compare periodical changes. In addition to that while buying stock, investors act aggressively because they believe they can make a significant profit. Investors who lack trust, on the other hand, can only buy a small amount of stock.

Rana and Vibha (2017) conducted a study on marital status and Investment preferences. The focus of this study is to analyse the impact of marital status on investment preferences. Finance plays a very important role in everyone's life and investment is an instrument that drives. Everyone whether single or married wants to be financially independent as they go for secured an investment which helps them to accumulate more wealth. The study reveals that being single is more advantageous as they are free to take financial decisions. While the biggest challenge for the married is that they need to discuss every financial plan with their partners. The study has revealed that there is a significant impact of marital status and gender on the investment behaviour of individuals. Both men and women respond to risk differently and women when compared to men are more risk-averse as per their behaviour. The study also focuses on divorced and widowed individuals who encounter a major change in their lives when they become single. One of the biggest challenges they face in this situation is to re-evaluate their long-term investment strategies to meet financial goals and needs. It becomes necessary for them to cope up with emotional stress before facing financial stress if any. Planning for future financial plans like retirement, health care, long term investment and children education comes into the context.

Christiansen, Joensen, and Rangvid (2011) conducted a study on the effects of marriage and divorce on financial investments. The study focuses on how the changes in marital status impact the financial decision making of individuals. As an alternative to the traditional approach of comparing different kind of investors like singles, married, and divorced, the study focuses to use a difference-indifference estimation strategy to compare individuals (before and after marriage) with that of the benchmark investors to study the differences as well as various related aspects. The investigation is also to know about the count of people who go for the stock market and also those who prepare risk portfolios. As per the findings, it was revealed that women tend to invest more in stocks after marriage while they decrease it when they are divorced. While on the other hand men invest less in stock after marriage and will increase their investment when they are divorced. The study also investigates the impact of gender and marital status on portfolio allocations by comparing one group of investors 
(single women) with that of another group of investors (married women). The concerns with such comparison are that firstly the single investors may differ from married Investors in allocating their portfolios due to some influences or behavioural traits. The second is that some singles have never married, or few have married but go separated, under such circumstances the way they perceive the information sets may differ from one another. This is how the changes in the marital status change the portfolio choice preferences of both men and women.

Vasagadekar (2014) conducted a study on investment awareness among Indian working women with special reference to Pune city. The objective is to study the investment behaviour and pattern of Indian working women in different sectors in Pune city and also to know their risk-bearing capacity while investing. The study focuses on various social demographic variables which are dependent on each other. Women wish to be financially independent and secured to fulfil their future needs. As the life expectancy of women is comparatively high when compared to men, it becomes important for them to plan their investments carefully to maintain their lifestyle throughout. It is seen in metro cities that the women are career-oriented and hence prefer not to get married and adopt children to become single parents. In such a situation, it becomes necessary for them to be financially independent to fulfil their needs as well as the needs of a new child. While it comes to divorced people, it is seen that the rate is increasing day by day and hence it is necessary for them to be financially independent as well and also to have sound investment to secure their future needs. The paper also reveals about women not being risk-averse while making investment decisions. They educate themselves about various avenues but invest in few comparatively, so it is important for them to take bold decisions while investing.

Bansal and Zahera (2018) conducted a study on do investor's exhibit behavioural biases in investment decision making. The purpose of this paper is to take a look at and describe various biases in investment decision-making considering the areas in behavioural finance. It additionally consists of a number of analytical and foundational works and the way this has advanced through the years to make behavioural finance a well-established study. The study reveals other behavioural patterns of men or women investors, institutional traders, and financial advisors. The findings revealed that the era of human emotions, behaviour, and sentiments was started which was earlier dominated by the study on the financial market. The study was inclined not only towards financial advisors and investors but also focused more on their behaviour to know about the biases that influence their decisions. The study will be helpful for the researchers to dig deep into the topic and make improvements if any. In addition, the companies as well as advisors can practically apply this before giving suggestions on investments. This will help investors not only recognize the behavioural biases but also make sound investments in order to minimize their risk.

Sahi and Arora (2012) published a paper on psychological biases of individual investors and financial satisfaction states that traditional finance concept is primarily based totally at the precept of maximization of application and explains how alternatives are made via way of means of rational human beings. Although the concept gives several insights, a remark of the real conduct of human beings became visible to be unique from what the concept predicted. Human beings have feelings and ideas that assist to clear out the content material from his or her environment. Thus, biases are not constantly bad, as at times, those biases can assist the character investor to pick out the great route of movement from the more than one opportunity and permit committing the much less high-priced mistakes, thereby assisting the character to obtain satisfying behaviour. This paper pursuit to discover the investor biases and notice whether or not they are associated with the monetary delight of the individuals. The consequences confirmed that overconfidence bias, reliance on the professional bias, and self-manage biases have a great affiliation with monetary delight levels. This examines gives in 
addition insights into investor conduct and paves the manner for numerous opportunities for future research.

Madaan and Singh (2016) conducted an analysis of behavioural biases in investment decision making. Individual decision making is affected by numerous biases in the growing discipline of behavioural finance. Therefore, this look is likewise one in all any other attempt to evaluate the effect of behavioural biases in funding decision-making in the National Stock Exchange. A questionnaire was floated, and a survey was conducted among 243 investors. In the existing study, four behavioural biases have been reviewed namely, overconfidence, anchoring, disposition effect and herding behaviour. The effects display that overconfidence and herding bias have a positive effect on funding decision. The investigation inferred that financial backers have restricted information and are inclined towards settling on mental mistakes while dynamic. The study also focused on the behavioural aspects which impact the decision making of individual investors.

Budhiraja, Raman, and Bhardwaj (2018) conducted a study on the impact of behavioural finance on investment decision making. Traditional finance theories advise that people make rational funding choices after cautiously thinking about the hazard and go back to elements to maximise their gains even as restricting their losses. Behavioural finance demanding situations the conventional financial idea and indicates that more than one biases affect the man or woman funding choices. The studies paper objectives to recognize how those biases affect the funding selection making system and what steps may be taken via way of means of man or woman traders to make rational choices. Analysing how realistic issues limit man or woman selection making, the paper concludes that man or woman traders want to cautiously mine records and remember outside elements earlier than task investments. The study reveals that behavioural finance is a field of study that proposes that venture choices are impacted by mental and enthusiastic elements generally. Behavioural finance is a field of study that proposes that venture choices are affected by mental and passionate components generally.

Dewan, Gayatri, and Dewan (2019) conducted a study on the investment behaviour of individual investors and corporate from Southern India. The current investigation expects to recognize the elements affecting the speculation conduct of corporate and individual investors and to direct a near report on the venture conduct of corporate and individual investors from South India. The analyst has distinguished an aggregate of four factors that effectively address the venture conduct of corporate and individual investors. These elements are primarily; Investor-related variables, market or natural components, speculation related factors, and friends' explicit elements. The comparative analysis of corporate and individual investors also showed that the investment behaviour of corporate and individual investors differs significantly from South India.

Verma (2016) conducted a study on the impact of behavioural biases in investment decision making and strategies. Behavioural finance plays an important role in investment decision making today. Currently, the investor makes a variety of decisions. Various options are available to investors in the market as they make investment decisions. Decision making means the final choice. With the best alternatives available to investors in the market, some investment decisions are simple and other investment decisions are complex and require a multi-faceted approach. This study evaluates and identifies the behavioural distortions in the decision-making process of investors when making investment decisions, as well as the effects of the behavioural distortions in decision-making. Behavioural biases generally vary in the judgments that arise in the given situation and lead to irrational decisions. These studies focus on some of the behavioural biases that influence investors' investment decisions.

Upadhyay (2019) conducted a study on the behavioural decision of individual investors in Ahmedabad. Behavioural finance is an evolving field that examines how psychological factors 
influence decision-making under unsafe conditions. Behavioural finance is one of the important things we need to know to understand people's mindset about how they think about different things when investing in different investment opportunities. Through this research, we got to know the mindset of people who invest in various investment opportunities. What do you think of investing? This article tries to discover the main influence of certain concepts of behavioural financing such as super consciousness, perception, representativeness and cognitive dissonance of anchoring, aversion, close framing, and regret. Mental accounting about the decision-making process of individual investors on the stock exchange. We performed primary research by developing a structured questionnaire and collecting a sample of 181 Ahmedabad investors. The main objective was to understand the effects of behavioural financing on investors and to examine the effects and relevance of behavioural financing in investor investment decisions. Noting that the secondary objective of our study was to understand the factors that affect investors while investing and to examine the concepts of behavioural finance and the various theories related to it.

Another wellspring of concern is the distinction in abundance among singles and wedded people. Hitched couples hold significantly higher abundance than single people, even subsequent to controlling for the presence of two workers in a wedded family unit. The examination on hazard resistance finds that ladies are more danger unwilling than men, however, the proof is a long way from convincing. The writing additionally finds that ladies will in general contribute their retirement resources more moderately than men.

Kansal and Singh (2018) conducted a study on determinants of overconfidence bias in the Indian stock market. The reason for this article is to play out an exploratory investigation of the demographic factors and investor attributes that lead to changes in the degrees of super cognizance and its components in people. A review was directed to inspect the determinants of super awareness and its segments. The four parts of super awareness considered for the examination are "better than average effect", "planning errors", "self-attribution" and "positive illusion". The gathered information is dissected utilizing the t-test, ANOVA, and normal least squares regression. The outcomes show that high workers have more wards, share pay obligations, have a high speculation recurrence, more limited time skyline and greater venture insight, and putting resources into enormous cap stocks is bound to be excessively cognizant. The examination additionally presumes that gender, age, and general instruction don't influence super awareness.

In this review, we are going to examine the cognitive bias of the investors according to behavioural finance theory. The further explanation was examined by this researcher (Asab). Cognitive bias is divided into two parts. Parts of cognitive bias are heuristics and prospect theory. Heuristics explains availability biases, gambler fallacy, availability biases, anchoring and overconfidence. Prospect theory explains loss aversion, regret aversion, self-control, and mental accounting.

Overconfidence explains the high turnovers and poor performance of the investors, (Barber, 2011) describes that the second variety of overconfidence is a belief that one is better than the median person. A reasonable amount of proof shows that the better-than-average and overestimation varieties of overconfidence relate to higher levels of trading by investors.

\section{RESEARCH METHODOLOGY}

Analytical techniques were classified mostly on qualitative data.

\section{Qualitative method}

In this, questions about why and how people behave and the reason behind it are highlighted. It provides in-depth information about human behaviour. This research method is commonly used to understand their thoughts and experiences. 


\section{The Sources of the qualitative method are as follows}

Basically, qualitative based data is general, and it can be collected from literature reviews, interviews, questionnaires or from observations. The study is conducted in the need to understand the savings and investment pattern of single-parent earner and the impact of behavioural finance on their decision.

\section{SCOPE OF THE RESEARCH}

To throw light on Investment pattern and which factors will impact the investment strategy of the single-parent earner population in South Asian countries of India, Nepal, Bangladesh, Pakistan and Srilanka.

\section{OBJECTIVES OF THE STUDY}

- To understand the type of investment of single parents.

- To analyze whether age has an impact on the risk of investment of the single parent.

- To evaluate the time horizon of investment done by single parents.

- To evaluate the percentage of the savings done by single parents.

- To analyze what encourages the single parent to do the savings and invest.

\section{DATA COLLECTION}

Primary data is collected through a questionnaire that was distributed as a google form (online survey, Telephonic Calls). The questionnaire includes questions with multiple choices and so on.

For the report, the required information has been obtained from various secondary sources of data which includes articles from journals, newspapers etc, research papers, etc.

\section{Purposive Sampling}

\section{SAMPLING DESIGN}

This method of sampling is appropriate because when we need a specific type of sample/respondents (Single earning parent), using the purposive technique allows us to select respondents based on the purpose of this sample. This technique is also known as judgment, selective or subjective sampling. Target population: This research is focused on all the single earning parents across the South Asian countries of India, Nepal, Bangladesh, Pakistan and Srilanka.

\section{Questionnaire Method}

\section{SAMPLING FRAME}

To get their response, we sent them google forms with questions to our respondents.

\section{Sample Size}

The sample size we targeted was $200+$, and we had circulated the forms to more than 250 individuals.

\section{Sample Area}

South Asian countries of India, Nepal, Bangladesh, Pakistan and Srilanka.

\section{LIMITATIONS OF THE STUDY}

- Responses are subjected to the bias and prejudices of the respondents.

- Findings of this study would be purely on the data from the sample respondents. So, it may not be possible to generalise to universal investment behaviour. 


\section{ANALYSIS AND INTERPRETATION}

Table 1. The demographic characteristics of the respondents

\begin{tabular}{|c|c|c|c|}
\hline & Categories & \multicolumn{2}{|c|}{ Respondents } \\
\hline & & Count & Percentage (\%) \\
\hline Age & $20-30$ & 49 & 24.1 \\
\hline & $31-40$ & 46 & 22.7 \\
\hline & $41-50$ & 65 & 32.0 \\
\hline & Above 50 & 43 & 21.2 \\
\hline Marital status & & $\mathbf{2 0 3}$ & $\mathbf{1 0 0}$ \\
\hline & Married & 80 & 39.4 \\
\hline & Divorced & 78 & 38.4 \\
\hline & Separated & 23 & 11.3 \\
\hline & & 22 & 10.8 \\
\hline Education & Undergraduate & $\mathbf{2 0 3}$ & $\mathbf{1 0 0}$ \\
\hline & Postgraduate & 67 & 33.0 \\
\hline & Professional & 76 & 37.4 \\
\hline & Others & 40 & 19.7 \\
\hline & & 20 & 9.9 \\
\hline & & $\mathbf{2 0 3}$ & $\mathbf{1 0 0}$ \\
\hline
\end{tabular}

\section{Interpretation}

The Age of the Respondent is required because it might have an influence on the spending habit of the respondent. Most of the respondents are in the age group 41-50. The remaining sample is almost equally divided among the other three age groups 20-30, 31-40 \& Above 50. The Marital status of the Respondent is required because describes a person's relationship with a significant other also known as Civil status. Most of the respondents are classified as Married or Unmarried category. The categories such as Divorced or separated are lesser in number when compared to the other categories. The number of respondents in terms of educational qualification is required because it might have an influence on the spending habit of the respondent due to the changes in education level. The total sample size is 203 and we have considered the respondents with different educational levels such as Undergraduate, Professional, Postgraduate and others, where most respondents are from the PG category.

Table 2. The sources of the information respondents avail for their investments

\begin{tabular}{|c|c|}
\hline Information & Number of respondents \\
\hline Relatives & 72 \\
\hline Friends & 113 \\
\hline Journal and magazines & 43 \\
\hline Advisors & 73 \\
\hline Websites & 1 \\
\hline Self & 3 \\
\hline
\end{tabular}




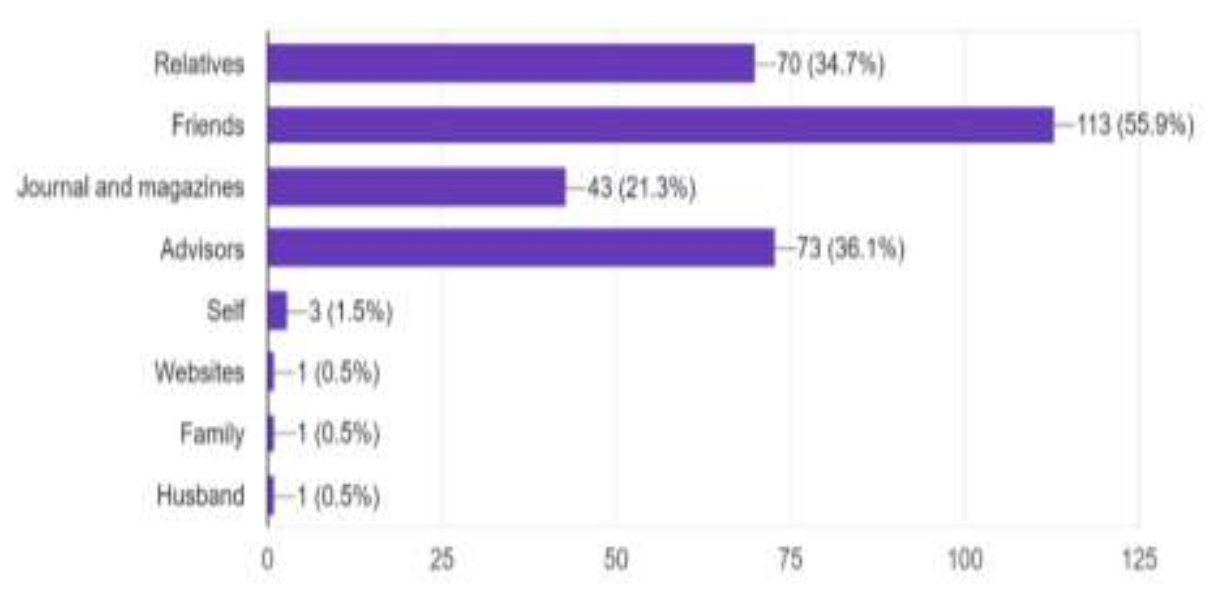

Figure 1. The sources of the information respondents avail for their investments

\section{Interpretation}

The majority of the respondents get their investment information from their friends, followed by relatives and advisors. A minimal number of respondents get their investment information from selfanalysis, websites, and family.

\section{Following are the various Behavioural Factors influencing investment decisions}

Table 3. Responses reflecting the overconfidence level of the respondents

\begin{tabular}{|l|l|l|l|}
\hline \multicolumn{2}{|l|}{ I am an experienced investor } & \multicolumn{2}{l|}{$\begin{array}{l}\text { I am confident about my own investment } \\
\text { opinions than opinions from my friends or } \\
\text { advisor }\end{array}$} \\
\hline Strongly Agree & 11 & Strongly Agree & 07 \\
\hline Agree & 74 & Agree & 117 \\
\hline Neutral & 104 & Neutral & 69 \\
\hline Disagree & 0 & Disagree & 0 \\
\hline Strongly Disagree & 14 & Strongly Disagree & 10 \\
\hline $\begin{array}{l}\text { I have the ability to choose investments } \\
\text { when their performance is better than } \\
\text { market performance }\end{array}$ & I go for riskier investment options \\
\hline Strongly Agree & 12 & & \multicolumn{2}{l|}{} \\
\hline Agree & 113 & Strongly Agree & 08 \\
\hline Neutral & 68 & Agree & 64 \\
\hline Disagree & 0 & Neutral & 94 \\
\hline Strongly Disagree & 10 & Disagree & 0 \\
\hline
\end{tabular}




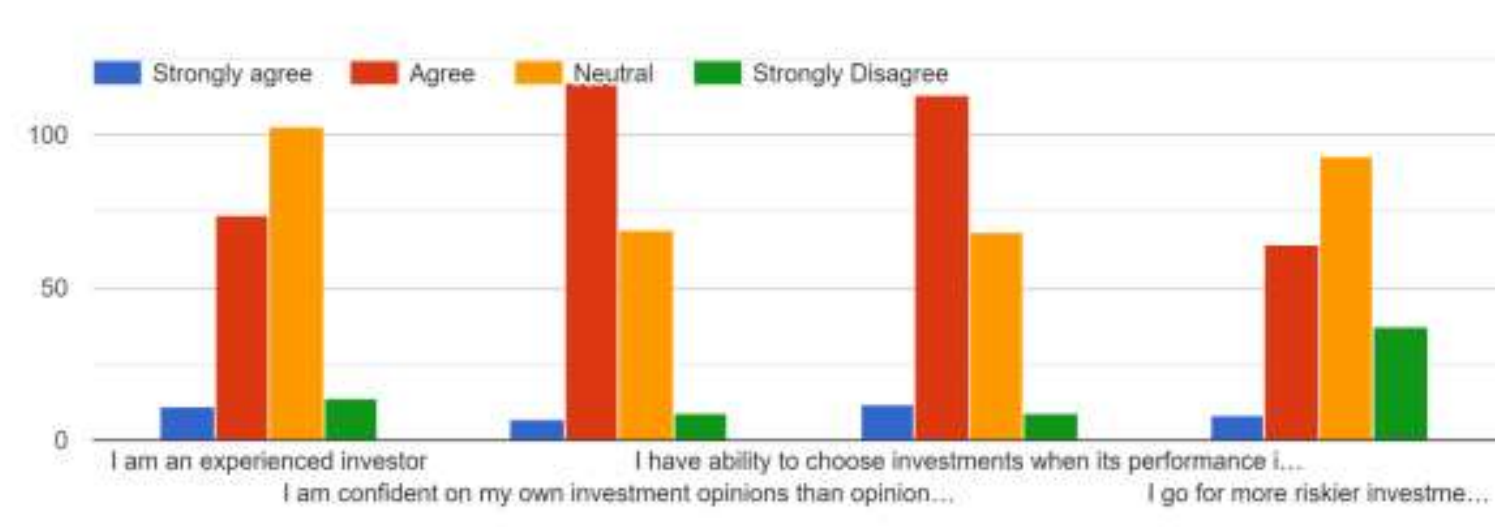

Figure 2. Responses reflecting the overconfidence level of the respondents

\section{Interpretation}

From the above data, we can see that most of the audience were confident about their investment opinions and have basic knowledge about it. And also, more than $64 \%$ of them prefer to go for lowrisk related investment rather than having a higher risk. Hence, we can say that most of the investors are confident about the investment decisions they have made.

Table 4. Responses reflecting the Loss aversion nature of the respondents

\begin{tabular}{|l|l|l|l|}
\hline $\begin{array}{l}\text { I am concerned more about losses in } \\
\text { investment than substantial gain }\end{array}$ & \multicolumn{2}{l|}{$\begin{array}{l}\text { I do not increase my investment when the } \\
\text { performance of the market is poor }\end{array}$} \\
\hline Strongly Agree & 15 & Strongly Agree & 17 \\
\hline Agree & 98 & Agree & 103 \\
\hline Neutral & 83 & Neutral & 79 \\
\hline Strongly Disagree & 07 & Strongly Disagree & 04 \\
\hline \multicolumn{4}{|l|}{} \\
\hline $\begin{array}{l}\text { I invest in low return, guaranteed } \\
\text { investment over investments that carry a } \\
\text { higher risk }\end{array}$ & $\begin{array}{l}\text { I sell stocks that increase in value very } \\
\text { quickly }\end{array}$ \\
\hline Strongly Agree & 15 & Strongly Agree & 13 \\
\hline Agree & 89 & Agree & 76 \\
\hline Neutral & 90 & Neutral & 86 \\
\hline Strongly Disagree & 09 & Strongly Disagree & 28 \\
\hline
\end{tabular}




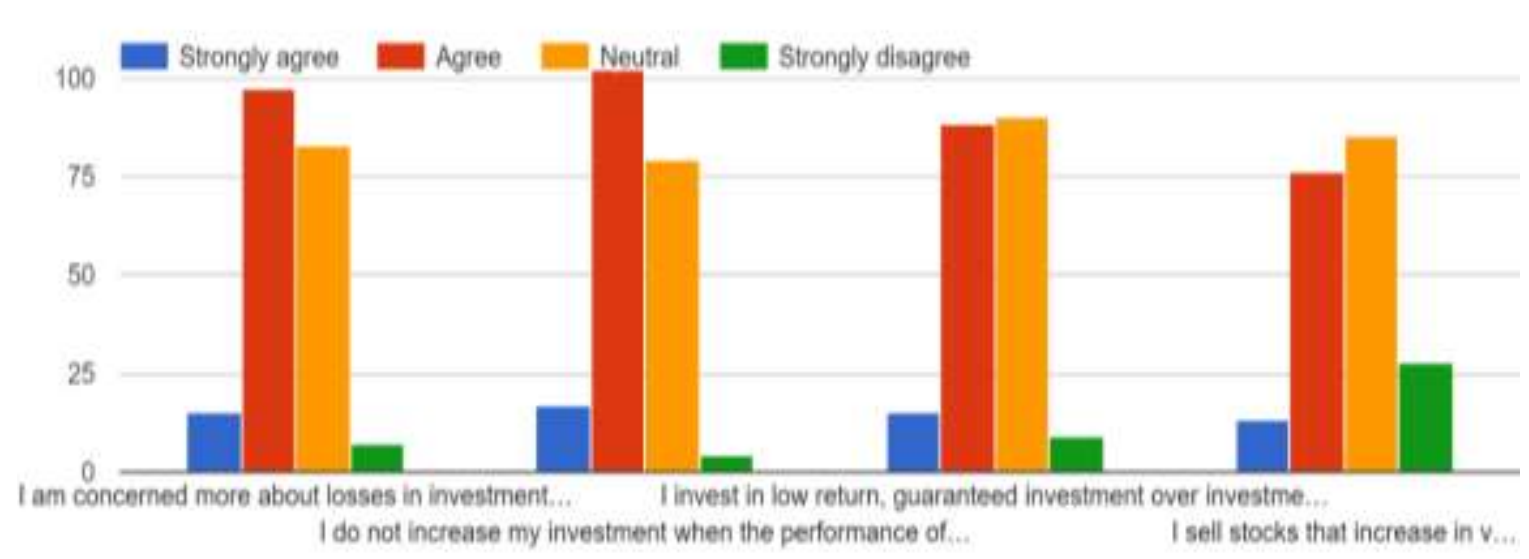

Figure 3. Responses reflecting the Loss aversion nature of the respondents

\section{Interpretation}

From the above data, it is clear that more than $60 \%$ of the investors are always concerned about the loss they might encounter in their investment and hence they prefer to invest in low return with guaranteed returns. Hence, the Loss aversion factor does have an impact on their decision-making pattern.

Table 5. Responses reflecting the availability biased nature of the respondents

\begin{tabular}{|l|l|l|l|}
\hline $\begin{array}{l}\text { I would go for an investment where my } \\
\text { friends or relatives have achieved higher } \\
\text { returns }\end{array}$ & I rely on internet sources to make investment decisions \\
\hline Strongly Agree & 22 & Strongly Agree & 12 \\
\hline Agree & 114 & Agree & 112 \\
\hline Neutral & 63 & Neutral & 68 \\
\hline Strongly Disagree & 04 & Strongly Disagree & 11 \\
\hline $\begin{array}{l}\text { I would invest in avenues recommended by } \\
\text { my friends or relatives }\end{array}$ & $\begin{array}{l}\text { I would rely on the information given by financial } \\
\text { advisors }\end{array}$ \\
\hline Strongly Agree & 24 & Strongly Agree & 37 \\
\hline Agree & 118 & Agree & 105 \\
\hline Neutral & 58 & Neutral & 60 \\
\hline Strongly Disagree & 03 & Strongly Disagree & 01 \\
\hline
\end{tabular}




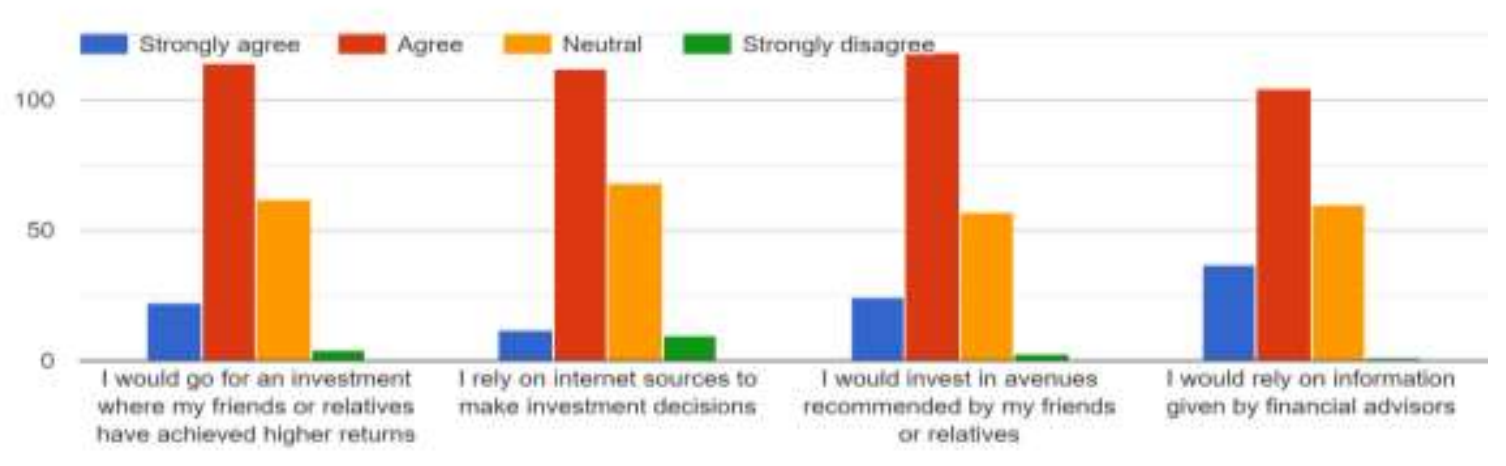

Figure 4. Responses reflecting the availability biased nature of the respondents

In terms of choosing a type of investment, the majority of the investors tend to choose where their friends or relatives have made more profits/higher returns than those stocks which are recommended by their friends/relatives. And they prefer to get information from financial advisors.

Table 6. Responses reflecting the mental accounting nature of the respondents

\begin{tabular}{|c|c|c|c|}
\hline \multicolumn{2}{|c|}{$\begin{array}{l}\text { I would rather invest where my friends have } \\
\text { made better returns }\end{array}$} & \multicolumn{2}{|c|}{$\begin{array}{l}\text { I make decisions from the information I } \\
\text { retrieve from the Internet. }\end{array}$} \\
\hline Strongly Agree & 36 & Strongly Agree & 37 \\
\hline Agree & 120 & Agree & 100 \\
\hline Neutral & 40 & Neutral & 50 \\
\hline Strongly Disagree & 07 & Strongly Disagree & 16 \\
\hline \multicolumn{4}{|c|}{ I would rely totally on advice given by financial advisors } \\
\hline Strongly Agree & 58 & & \\
\hline Agree & 89 & & \\
\hline Neutral & 48 & & \\
\hline Strongly Disagree & 08 & & \\
\hline
\end{tabular}

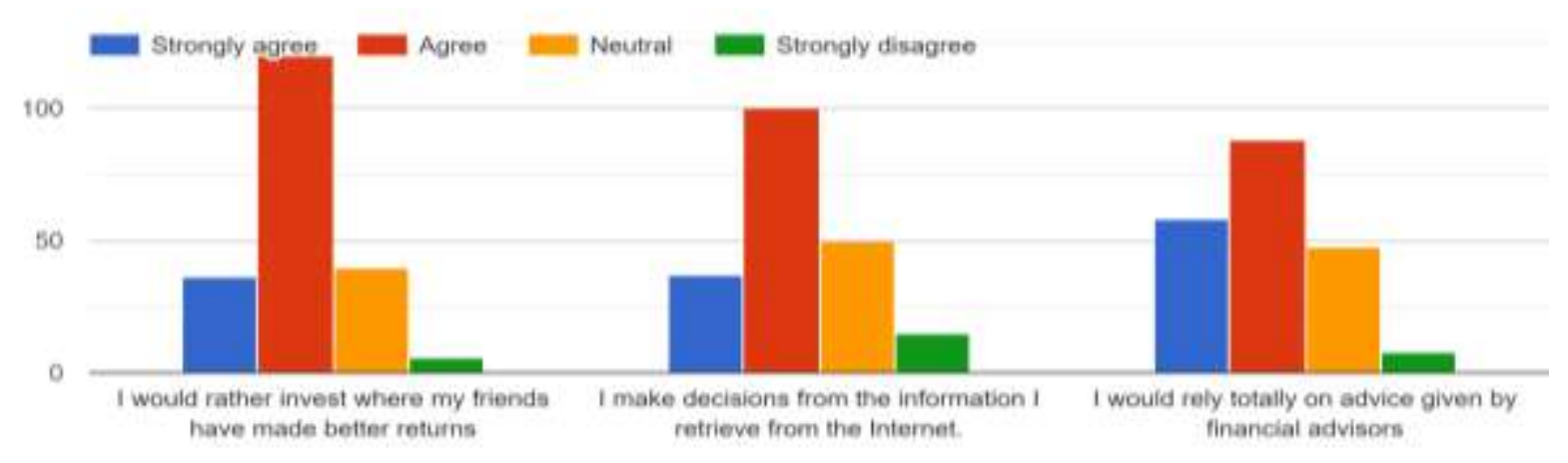

Figure 5. Responses reflecting the mental accounting nature of the respondents 
From the data available, we can infer that most of the investors prefer to choose the type of investment which their peer group had made and have made better returns. Whereas more than $67 \%$ of them agreed that they can rely on the information which is available on the internet which includes share reports, news based on stocks and companies and advisors who provide in-depth reports regarding the company's financials.

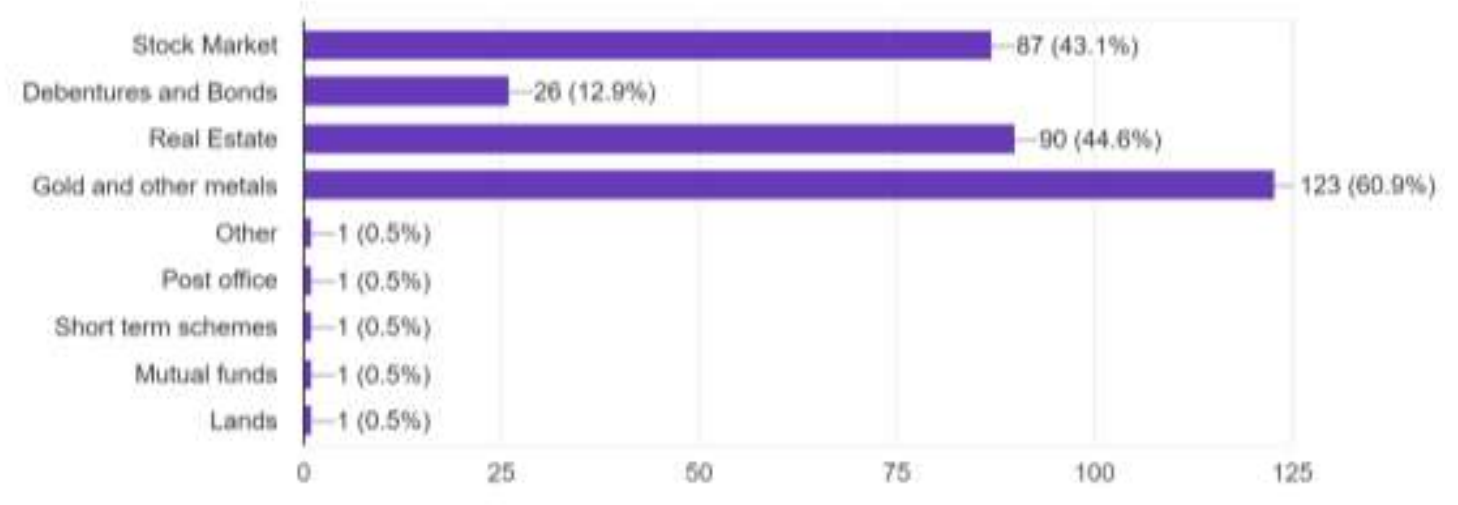

Figure 6. The type of investment the respondents prefer the most

\section{Interpretation}

From the above graph, we can say that majority of the investors, i.e., prefers gold and other metals which provides stable returns whereas more than $40 \%$ of them chose real estate and the stock market. Few of the investors were interested in debentures and the remaining prefers to invest in mutual funds or short-term schemes available.
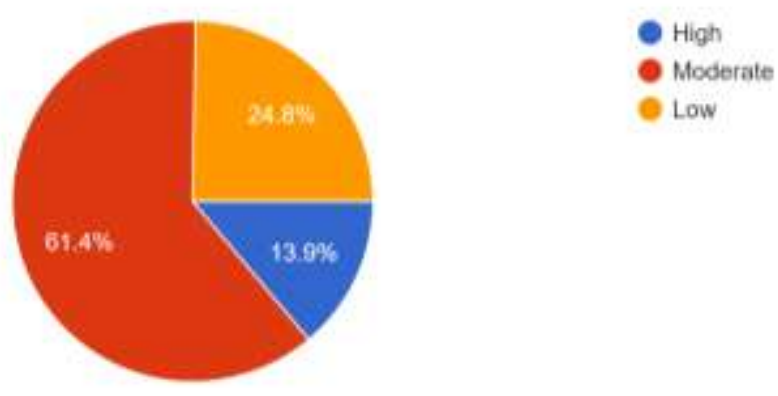

Figure 7. The willingness of respondents to take the risk on their investment

\section{Interpretation}

According to the data available, we can say that majority of the investors are willing to take a moderate amount of risk for their investment whereas $24.8 \%$ of them prefer low risk-related investment. And only $14 \%$ of them were attracted towards high-risk related investment. 


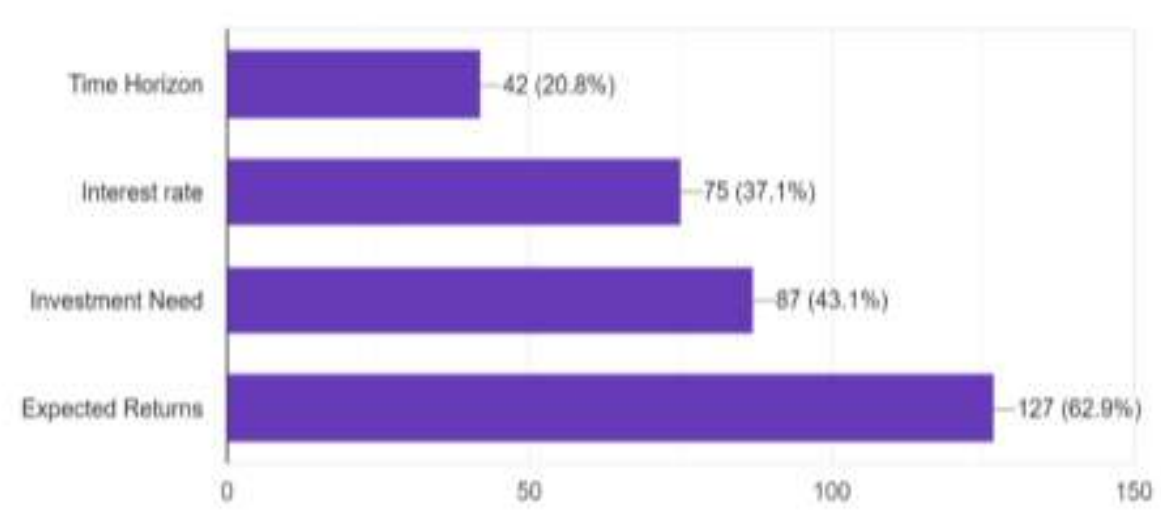

Figure 8. The different aspects which influence their investment decisions:

\section{Interpretation}

From the above graph, we can conclude that aspects such as the expected amount/ percentage of returns on their investment and the investment need which they have can have more influence on their decisions. Whereas $37 \%$ of them chose Interest rate. And the remaining $20.8 \%$ were confident that the overall time period/horizon of their investment have more impact on their decisions related to the investment.

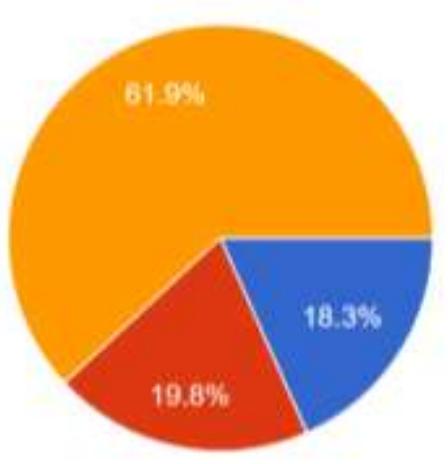

Losses

Gains

Both (a) and (b)

Figure 9. The concerns of the respondents while taking major financial decisions

\section{Interpretation}

With regards to the financial decision, the majority of the investors (70 \%) are more concerned about both gains and losses which they might encounter. Whereas $19 \%$ of them were concerned about the gains they will get out of their investment. And the remaining $18 \%$ of them were more concerned about losses in their investment. 


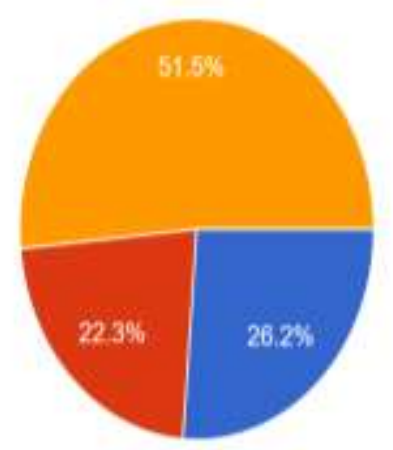

A product with low average retum but almost no risk of loss of the initial investment

A product with high average return but some risk of losing part of initial investment

A mixture of two products

Figure 10. The type of investments the respondents prefer while investing

When it comes to choosing a type of investment product from the given options, the majority of them went with a mixture of both low /average returns with no risk and investment with higher risk and a higher possibility to get returns. Whereas around $26 \%$ of them chose the safer option with minimal or no risk and stable lower return. And the remaining $22 \%$ of investors were in favour of getting more returns with higher risk-related investment.

\section{INFERENTIAL STATISTICS}

Inferential statistics are methods for using surveys to generalize about the populations from which they were taken. As a consequence, it's important that the sample accurately reflects the population. Sampling is the tool for accomplishing this. It is often recognized as one of the most important branches of statistics.

Inferential statistics are derived from the assumption that sampling is susceptible to error, and thus a sample cannot be assumed to perfectly represent the entire population. The methods of inferential statistics are:

1) The estimation of parameter: This means that taking a statistic from the sample and using it to say something about the given population parameter.

2) Testing of statistical hypotheses: This is where you can use collected data to summarize research questions.

\section{The Assumptions for the test are:}

- Sample is a purposive sample

- Sample size is large (203)

- Every unit in the sample is mutually categorized.

- Confidence level taken: $95 \%$, Hence Alpha: 0.05

\section{CHI-SQUARE TEST}

For evaluating relationships between two or more categorical variables, the Chi-Square test is widely used. There are variables that may be categorical (qualitative) or quantitative in nature (numerical). Assumptions of the Chi-Square Test:

- The categories are mutually exclusive, meaning that each subject belongs to only one category

- The data should be in the form of frequencies or counts in a given type, not percentages.

- The data should be in the form of frequencies or counts in a given type, not percentages.

- When more than $20 \%$ of the expected frequencies have a value of less than 5 then 
Chi-square cannot be used. To tackle this problem: Either one should combine the categories only if it is relevant or obtain more data

\section{The objective of the test: To analyse whether there is a relationship between the level of income and percentage of investment.}

Construction of Statistical Hypothesis

Research Hypothesis: Maybe the income level and percentage of investment are significantly associated

Hypothesis (Ho): income level and \% of investment is not significantly associated

Alternative Hypothesis $\left(\mathrm{H}_{1}\right)$ : income level and \% of investment) are significantly

associated

Errors in Hypothesis Testing

Type-I Error: P (Reject H0 / Not reject $\mathrm{H} 0)=\alpha$

$\mathrm{P}$ (Income level and percentage of investment are dependent / Income level and percentage of investment are Independent $)=0.05$

Type-II Error: P (Not Reject H0 / Reject H0) $=\beta$

$\mathrm{P}$ (Income level and percentage of investment are Independent / Income level and percentage of investment are dependent $)=\beta$

Assumptions:

1. The sample is a purposive sample

2. The Sample size is enough

Table 7. The dependency of investment on income level: Observed frequency Test Procedure

\begin{tabular}{|c|c|c|c|c|c|}
\hline INCOME LEVELS & $<10 \%$ & $>40 \%$ & $10-20 \%$ & $20-30 \%$ & Grand Total \\
\hline $3,00,000-5,00,000$ & 13 & 0 & 21 & 11 & 45 \\
\hline $5,00,000-10,00,000$ & 13 & 2 & 19 & 43 & 77 \\
\hline Above $10,00,000$ & 2 & 6 & 13 & 21 & 42 \\
\hline Up to 3,00,000 & 24 & 0 & 14 & 1 & 39 \\
\hline Grand Total & 52 & 8 & 67 & 76 & 203 \\
\hline
\end{tabular}

Construction of Test Statistics:

Under the Null Hypothesis, we calculate Expected Frequencies and then compare observed frequencies with expected frequencies. If both are the same or very close, then Ho is not rejected. Because our Assumptions are true.

Formula:

Expected Frequency: (Row Total*Column Total)/Grand Total

Table 8. The dependency of investment on income level: Expected Frequency

\begin{tabular}{|c|c|c|c|c|c|}
\hline INCOME LEVELS & $<10 \%$ & $>40 \%$ & $10-20 \%$ & $20-30 \%$ & Grand Total \\
\hline $3,00,000-5,00,000$ & 11.5270936 & 1.773399015 & 14.85222 & 16.84729 & 45 \\
\hline $5,00,000-10,00,000$ & 19.7241379 & 3.034482759 & 25.41379 & 28.82759 & 77 \\
\hline Above $10,00,000$ & 10.7586207 & 1.655172414 & 13.86207 & 15.72414 & 42 \\
\hline
\end{tabular}




\begin{tabular}{|c|c|c|c|c|c|}
\hline Up to $3,00,000$ & 9.99014778 & 1.536945813 & 12.87192 & 14.60099 & 39 \\
\hline & 52 & 8 & 67 & 76 & 203 \\
\hline
\end{tabular}

P-Value:

The P-value is the probability of observing a sample statistic as extreme as the test statistic. Since the test statistic is a chi-square, we use the Chi-Square Distribution Calculator to assess the probability associated with the test statistic.

BY CALCULATION, WE FIND P LEFT AND RIGHT VALUE

FORMULA:

P-LEFT: CHISQ.DIST(X, DEGREE OF FREEDOM, CUMULATIVE)

P-RIGHT: CHISQ.DIST. RT (X, DEGREE OF FREEDOM)

P-LEFT:0.99999807

P-RIGHT:1.93095E-07

WE TAKE MIN AMONG P-RIGHT AND P-LEFT AS P-VALUE

Formula:

$=$ CHISQ.TEST $($ actual range, expected range)

$P$ VALUE $=1.93095 \mathrm{E}-07$

The above P-value is less than the $\alpha$ value i.e.,0.05

So, the decision is t to reject Null Hypothesis

Conclusion: There exists a significant relationship between the level of income and percentage of investment

The objective of the test: To analyze whether there is a relationship between the type of investment and the risk-taking ability.

\section{Construction of Statistical Hypothesis}

Research Hypothesis: Maybe there can be a relationship between the type of investment and risktaking ability

Null Hypothesis (Ho): There is no relationship between the type of investment and risk-taking ability Alternate Hypothesis (H1): There is a relationship between the type of investment and risk-taking ability

Errors in Hypothesis Testing

Type-I Error: P (Reject H0 / Not reject $\mathrm{H} 0)=\alpha$

$\mathrm{P}$ (Type of investment and risk-taking ability are dependent/Type of investment and risk-taking ability are dependent Independent) $=0.05$

Type-II Error: P (Not Reject H0 / Reject H0) $=\beta$

$\mathrm{P}$ (Type of investment and risk-taking ability are independent/Type of investment and risk-taking ability are dependent) $=\beta$

Assumptions:

1) Normal distribution is not necessary

2) The sample is purposive

3) All classifications are mutually exclusive 
Test Procedure:

Table 9. Type of investment and risk-taking ability: observed frequency

\begin{tabular}{|l|l|l|l|l|l|l|}
\hline $\begin{array}{l}\text { RISK TAKING } \\
\text { ABILITY }\end{array}$ & $\begin{array}{l}\text { Stock } \\
\text { Market }\end{array}$ & $\begin{array}{l}\text { Debentures } \\
\text { and bonds }\end{array}$ & Real Estate & $\begin{array}{l}\text { Gold and other } \\
\text { metals }\end{array}$ & others & Total \\
\hline High & 19 & 2 & 6 & 1 & 0 & 28 \\
\hline Low & 9 & 7 & 7 & 24 & 4 & 51 \\
\hline Moderate & 59 & 10 & 38 & 16 & 1 & 124 \\
\hline Grand Total & 87 & 19 & 51 & 41 & 5 & 203 \\
\hline
\end{tabular}

Construction of Test Statistics:

Under the Null Hypothesis, we calculate Expected Frequencies and then compare observed frequencies with expected frequencies. If both are the same or very close, then Ho is not rejected. Because our Assumptions are true.

Table 10. Type of investment and risk-taking ability: expected frequency

\begin{tabular}{|l|l|l|l|l|}
\hline $\begin{array}{l}\text { RISK TAKING } \\
\text { ABILITY }\end{array}$ & $\begin{array}{l}\text { stock market\& } \\
\text { debentures }\end{array}$ & Real Estate & $\begin{array}{l}\text { Gold and other } \\
\text { metals }\end{array}$ & TOTAL \\
\hline High & 14.62068966 & 7.03448276 & 6.344827586 & 28 \\
\hline Low & 26.63054187 & 12.8128079 & 11.55665025 & 51 \\
\hline Moderate & 64.74876847 & 31.1527094 & 28.09852217 & 124 \\
\hline Grand Total & 106 & 51 & 46 & 203 \\
\hline
\end{tabular}

The expected frequency counts are computed separately for each level of one categorical variable at each level of the other categorical variable.

From Calculation under the Null Hypothesis, we get Test Statistic $c^{2}=43.882943$

P-Value:

The P-value is the probability of observing a sample statistic as extreme as the test statistic. Since the test statistic is a chi-square, we use the Chi-Square Distribution Calculator to assess the probability associated with the test statistic.

BY CALCULATION, WE FIND P LEFT AND RIGHT VALUE

FORMULA:

P-LEFT: CHISQ.DIST(X, DEGREE OF FREEDOM, CUMULATIVE)

P-RIGHT: CHISQ.DIST. RT (X, DEGREE OF FREEDOM)

P-LEFT: 0.999999993

P-RIGHT6.78518E-09

WE TAKE MIN AMONG P-RIGHT AND P-LEFT AS P-VALUE

Formula:

$=$ CHISQ.TEST (actual range, expected range) 


\section{P-VALUE: 6.8E-09}

The above value is less than the $\alpha$ value i.e., 0.05

So, the decision is to reject Null Hypothesis

Conclusion: There Is a significant relationship between the type of investment and risk-taking ability

The objective of the test: To analyze whether there is a relationship between annual income and risk-taking ability.

Construction of Statistical Hypothesis

Research Hypothesis: Probably there is a relationship between annual income and risk-taking ability.

Null Hypothesis (Ho): There is no relationship between annual income and risk-taking ability. Alternative Hypothesis (H1): There is a relationship between annual income and risk-taking ability.

Errors in Hypothesis Testing

Type-I Error: P (Reject $\mathrm{H} 0$ / Not reject $\mathrm{H} 0)=\alpha$

$\mathrm{P}$ (Annual income and risk-taking ability are dependent / Annual income and risk-taking ability are Independent $)=0.05$

Type-II Error: P (Not Reject H0 / Reject H0) $=\beta$

$\mathrm{P}$ (Annual income and risk-taking ability/ $\mathrm{P}($ Annual income and risk-taking ability are dependent $)=\beta$

Assumptions:

1. Normal distribution is not necessary

2. The sample is purposive

3. All classifications are mutually exclusive

Table 11. Annual income and risk-taking ability: observed frequency

Test Procedure:

\begin{tabular}{|l|l|l|l|l|}
\hline INCOME BRACKET & High & Low & Moderate & Grand Total \\
\hline $3,00,000-5,00,000$ & 1 & 18 & 26 & 45 \\
\hline $5,00,000-10,00,000$ & 11 & 12 & 54 & 77 \\
\hline Above $10,00,000$ & 15 & 3 & 24 & 42 \\
\hline Up to 3,00,000 & 1 & 17 & 21 & 39 \\
\hline Grand Total & 28 & 50 & 125 & 203 \\
\hline
\end{tabular}

Construction of Test Statistics:

Under the Null Hypothesis, we calculate Expected Frequencies and then compare observed frequencies with expected frequencies. If both are the same or very close, then Ho is not rejected. Because our Assumptions are true.

The expected frequency counts are computed separately for each level of one categorical variable at each level of the other categorical variable. 
Table 12. Annual income and risk-taking ability: expected frequency

\begin{tabular}{|l|l|l|l|l|}
\hline EXPECTED VALUES & High & Low & Moderate & $\begin{array}{l}\text { Grand } \\
\text { Total }\end{array}$ \\
\hline $3,00,000-5,00,000$ & 6.206896552 & 11.08374 & 27.70935961 & 45 \\
\hline $5,00,000-10,00,000$ & 10.62068966 & 18.96552 & 47.4137931 & 77 \\
\hline Above $10,00,000$ & 5.793103448 & 10.34483 & 25.86206897 & 42 \\
\hline Up to 3,00,000 & 5.379310345 & 9.605911 & 24.01477833 & 39 \\
\hline Grand Total & 28 & 50 & 125 & 203 \\
\hline
\end{tabular}

From Calculation under the Null Hypothesis, we get Test Statistic $c^{2}=32.97817265$

P-Value:

The P-value is the probability of observing a sample statistic as extreme as the test statistic.

Since the test statistic is a chi-square, we use the Chi-Square Distribution Calculator to assess the probability associated with the test statistic.

BY CALCULATION, WE FIND P LEFT AND RIGHT VALUE

FORMULA:

P-LEFT: CHISQ.DIST(X, DEGREE OF FREEDOM, CUMULATIVE)

P-RIGHT: CHISQ.DIST. RT (X, DEGREE OF FREEDOM)

P-LEFT:0.99999879

P-RIGHT:1.2068E-06

WE TAKE MIN AMONG P-RIGHT AND P-LEFT AS P-VALUE

Formula:

$=$ CHISQ.TEST (actual range, expected range)

P-VALUE $=1.2068 \mathrm{E}-06$

The above value is less than the $\alpha$ value i.e .05

So,the decision is to reject the Null Hypothesis

Conclusion: There is a significant relationship between income level and percentage of investment

\section{FINDINGS}

Some of the findings from the competitive study on the impact of behavioural finance on the investment decision of a single parent are as follows:

- Most single parents are private employees

- The majority of single parents' income ranges from 5,00,000 to 10,00,000, this is the amount received annually basis which could be due to a rise in expenses and also due to a rise in educational level

- The number source of income in a single parent's family from 2 to 5 people, which allows them to save more and to invest properly.

- The majority of dependents in a single parent's family comprises of 2 to 5 . It shows the dependents are more, so the investing pattern of the single earner differs.

- The number of people having income from other sources is 2 being the highest in a family, but we can observe that people having other sources of income with 3 or more are the least with only 4. 
- We could find that most of the single parents were confident about their investment opinions and have basic knowledge about it. And more than $64 \%$ of them prefer to go for low-risk related investment rather than having higher risk as there is no room for a second chance to invest all over in the given situation.

- More than $60 \%$ of investors are still worried about future losses in their portfolios, so they tend to invest in low-risk, guaranteed-return investments. Therefore, the aversion factor to failure influences their pattern of decision making.

- In terms of choosing a form of investment, most investors prefer to select the shares/mutual funds recommended by their friends/relatives where their friends or relatives have made more profits/higher returns. They may still choose to collect details from financial advisors to be on the safer side.

- We can say that most investors choose to select the form of investment that their peer group has made. When more than $67 \%$ of them agreed that they could rely on the information available on the internet, which includes reports from companies, third party sites, individual's stories, and news. Based on stocks and companies and consultants that provide in-depth reports on the company's financials.

- We could see that most investors prefer gold and other metals because they have stable returns, while more than $40 \%$ prefer real estate and the stock market. Few investors are interested in debentures, with the remainder opting for other short-term investments.

- We could also see that most investors are willing to take a moderate amount of risk for their investment, while $24.8 \%$ prefer investments associated with low risk. And only $14 \%$ of them were drawn to investments associated with high risk.

- We can infer that factors like the estimated amount/percentage of returns on their investment and the investment need they have can have a greater effect on their decisions.

- Most investors (70\%) are more worried about the gains and losses they may face. When it comes to choosing an investment type, most of them went without risk with a combination of both low/average returns and even an investment of higher risk and higher return potential.

- From the statistical analysis, we could see that there was a significant level of relationship between the income level of a single parent and the percentage of investment they do. Also, there was a significant relationship between the risk-taking ability and the type of investment they have made.

\section{SUGGESTIONS}

As the survey was based on the investment decision of a single parent, it becomes very important to highlight the factors which can have a major impact on their investment. When they think about investing their savings, they need to get a clear picture of the options available to them and for that, as we have seen that most single parents rely on web-based information or try to get information from friends and family members. But when it comes to investing their hard-earned money, it is important to consult an advisor and go ahead. Also, it is very important to differentiate properly between short term and long-term goals based on your expectations and need for the investment and invest accordingly. And finally, if they have more than 2-3 number of dependents in a family, they should look for low risk associated investment.

\section{CONCLUSION}

The single parent and their investment decisions can be overwhelming in terms of managing parenting and money management. When a single parent steps ahead and invests their hard-earned savings, there 
is no room for an error. Basically, the study shows that the target audience usually ends up neglecting long term planning and want to invest with a minimal or low amount of risk involved. There is a need to differentiate properly between short term and long-term goal and to invest accordingly. Depending on your income and other sources of income in a family, you can calculate the risk you can afford to take while investing.

For example, if we see that the respondents from the survey had a fair amount of knowledge about an investment which gives them freedom while choosing the type of investment as per their requirements. Lately, it has become crucial to cover the risk before one makes an investment. Especially for single parents, the priority is on their children and hence the insurance cover must include their present living exp. and their education-related expenses. Since investors are treated as rational and normal, there can be many biases that can make an impact on individual's investment's decision making.

\section{REFERENCES}

Bansal, R., \& Zahera, S. A. (2018). Do investors exhibit behavioral biases in investment decision making? A systematic review. Qualitative Research in Financial Markets, 210-251.

Barber, O. (2011). The Behavior of Individual Investors. In G. Constantinides, \& M. H. Stulz, Handbook of the Economics of Finance (pp. 1533-1570). Elsevier.

Christiansen, C., Joensen, J. S., \& Rangvid, J. (2011). Understanding the Effects of Marriage and Divorce on Financial Investments: The Role of Background Risk Sharing. Economic Enquiry, 431-447.

Dewan, A., Gayatri, R., \& Dewan, R. (2019). A Research on Investment Behavior of Corporate and Individual Investors from Southern India. International Journal of Innovative Technology and Exploring Engineering (IJITEE), 1493-1501.

Budhiraja, K., Raman, T.V. \& Bhardwaj, G. N. (2018). IMPACT OF BEHAVIORAL FINANCE IN INVESTMENT DECISION MAKING. International Journal of Civil Engineering and Technology (IJCIET), 1151-1157.

Kansal, P., \& Singh, S. (2018). Determinants of overconfidence bias in Indian stock market. Qualitative Research in Financial Markets, 381-394.

Madaan, G., \& Singh, S. (2016). Behavioural Biases in Financial Decision Making. International Journal of Financial Research, 1-13.

Rana, S., \& Vibha. (2017). Marital Status and Investment Preferences. Online International Interdisciplinary Research Journal, 91-98.

Sahi, S. K., \& Arora, A. P. (2012). Psychological biases of individual investors and financial satisfaction. Qualitative Research in Financial Markets, 4(1), 6-25.

Upadhyay, D. (2019). A STUDY ON BEHAVIORAL FINANCE IN INVESTMENT DECISIONS OF INVESTORS IN AHMEDABAD. International Journal of Novel Research and Development, 103-114. 
Vasagadekar, P. (2014). A research paper on investment awareness among Indian working women with reference to Pune region. International Journal of Scientific \& Engineering Research, 5(6), 1333-1350.

Verma, N. (2016). Impact of Behavioral Biases in Investment Decision and Strategies. Journal of Management Research and Analysis, 28-30.

\section{Copyrights}

Copyright for this article is retained by the author(s), with first publication rights granted to the journal. This is an open-access article distributed under the terms and conditions of the Creative Commons Attribution license (http://creativecommons.org/licenses/by/4.0/) 